\title{
Resapan Dengan Koefisien Permeabilitas Batuan Desain Sumur Lapisan Bawah
}

\author{
Lies K Wilandari ${ }^{1}$, dan Kustamar ${ }^{1}$ \\ ${ }^{1,2}$.Dosen Jurusan Teknik Sipil Institut Teknologi Nasional Malang
}

\begin{abstract}
ABSTRAK
Banjir masih menjadi salah satu bencana yang menjadi perhatian, karena memiliki daya rusak yang cukup mengganggu, bahkan menimbulkan kerugian dan membahayakan keselamatan. Mayoritas banjir di dominasi oleh air yang merupakan akumulasi dari air limpasan permukaan, sehingga untuk mengendalikannya harus difokuskan pada upaya bagaimana memaksimalkan resapan air hujan ke dalam tanah. Mayoritas pemilik lahan pada daeran tangkapan hujan yang pada umumnya disebut daerah aliran sungai (DAS) adalah masyarakat. Oleh karenanya, dalam upaya pengendaliannya harus melibatkan masyarakat. Konstruksi sederhana yang cukup efektif digunakan adalah sumur resapan, karena memiliki kapasitas yang cukup besar akan tetapi mudah dibuat oleh masyarakat, dengan resiko yang relative kecil. Namun demikian dari tinjuan system drainase, penggunaan sumur resapan memerlukan biaya yang lebih besar dibandingjkan dengan pembuatan saluran drainase untuk mengalirkan hujan ke sungai. Oleh karenanya diperlukan upaya optimasi desain untuk mendapatkan biaya yang paling murah. Desain akan tepat jika digunakan data yang akurat, oleh karenanya dilakukan pengujian koefisien permeabilitas batuan bawah permukaan.
\end{abstract}

Keyword : Banjir, limpasan permukaan, desain sumur_resapan; koefisien_permeabilitas.

\section{PENDAHULUAN}

Banjir masih menjadi salah satu bencana yang menjadi perhatian, karena memiliki daya rusak yang cukup mengganggu, bahkan menimbulkan kerugian dan membahayakan keselamatan. Mayoritas banjir di dominasi oleh air yang merupakan akumulasi dari air limpasan permukaan, sehingga untuk mengendalikannya harus difokuskan pada upaya bagaimana memaksimalkan resapan air hujan ke dalam tanah. Mayoritas pemilik lahan pada daeran tangkapan hujan yang pada umumnya disebut daerah aliran sungai (DAS) adalah masyarakat. Oleh karenanya, dalam upaya pengendaliannya harus melibatkan masyarakat. Konstruksi sederhana yang cukup efektif digunakan ialah sumur resapan, karena memiliki kapasitas yang cukup besar akan tetapi mudah dibuat oleh masyarakat, dengan resiko yang relative kecil. Namun demikian dari tinjuan system drainase, penggunaan sumur resapan memerlukan biaya yang lebih besar dibandingjkan dengan pembuatan saluran drainase untuk mengalirkan hujan ke sungai. Oleh karenanya diperlukan upaya optimasi desain untuk mendapatkan biaya yang paling murah. Desain akan tepat jika digunakan data yang akurat, oleh karenanya dilakukan pengujian koefisien permeabilitas batuan bawah permukaan.

Upaya pengendalian disusun dengan orentasi maksimalisasi: penampungan air hujan di bawah permukaan tanah (bagian hulu), penampungan air banjir di palung sungai (bagian tengah), dan penyaluran air yang tidak bisa dimanfaatkan (bagian hilir). Maksimalisasi penampungan air hujan di bawah permukaan lahan akan efektif jika dilakukan dengan konservasi lahan yang diperkuat dengan penggunaan konstruksi sumur resapan fungsi ganda

Rendahnya kapasitas tiap sumur resapan menyebabkan penggunaan sumur resapan menjadi mahal, sehingga menjadi kendala saat dilakukan gerakan massal dengan anggaran masyarakat. Untuk hal tersebut diperlukan upaya peningkatan kapasitas sumur resapan, dan control kualitas air tanah.

\section{Koefisien Permeabilitas Tanah}

Permeabilitas tanah ialah kemampuan tanah untuk meloloskan atau mengalirkan air, yang diwakili besarnya kecepatan air dalam merembes ke dalam tanah, baik secara horizontal maupun vertical melalui pori-pori tanah. Kecepatan perembesan air ini dipengaruhi oleh tekstur tanah. Hukum Darcy menjelaskan tentang kemampuan air mengalir pada rongga-rongga (pori) dalam tanah dan sifat-sifat yang mempengaruhinya. Ada dua asumsi utama yang digunakan dalam penetapan hokum Darcy ini. Asumsi pertama menyatakan bahwa aliran fluida/cairan dalam tanah bersifat laminar. Sedangkan asumsi kedua menyatakan bahwa tanah berada dalam keadaan jenuh.

Menurut Sunjoto, koefisien permeabilitas tanah dapat diketahui menggunakan formulasi sebagai berikut: 

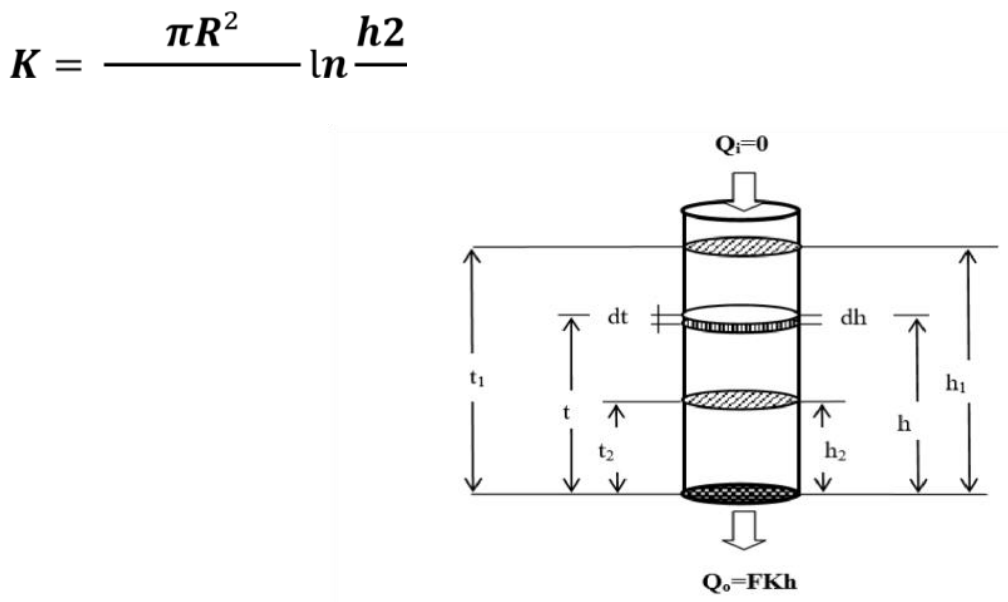

$F(t 2-t 1) \quad h 1$

Gambar 1. Skema Aliran dalam Lubang Bor

Formula tersebut adalah untuk menghitung Koefisien Permeabilitas tanah (K) menurut Forchheimer (1930), bila diketahui perubahan tinggi muka air fungsi waktu dalam bore hole dengan debit $\mathrm{Q}=0$ (air dituang dalam sekejap) Sunjoto (1988) membangun formula ini dengan asas:

1. Debit air masuk kedalam sumur diasumsikan konstan sama dengan Q. Hal ini sesuai dengan keadaan fisik yaitu dalam suatu durasi hujan akan ada debit dari atap yang masuk kedalam sumur.

2. Debit keluar (meresap) adalah sama dengan faktor geometrik kali koefisien permeabilitas fungsi ketinggian air dalam sumur $\boldsymbol{Q o}=\boldsymbol{F} \boldsymbol{K} \boldsymbol{h}$ (Forchheimer, 1930).

3. Formula unsteady flow condition ini menjadi sama dengan formula Forchheimer (1930) bedanya adalah yang terakhir ini adalah steady flow condition. Bila waktu tak terhingga maka formula Sunjoto akan sama menjadi steady flow condition dan formulanya akan sama persis dengan formula Forchheimer (1930).

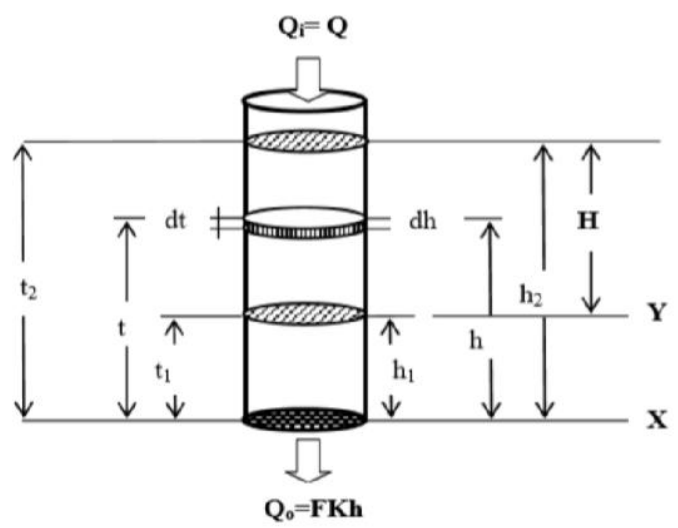

Gambar 2. Skema Aliran dalam Sumur

\section{METODE}

Kegiatan penelitian berupa: penggalian tanah sesuai desain sumur, pengambilan benda uji, pengujian koefisisen permeabilitas di laboratorium tanah. Data hasil uji laboratorium digunakan sebagai dasar analisa desain sumur resapan. Desain dilakukan dengan berbagai formula, kemudian dibandingkan dengan data kapasitas sumur hasil pengamatan lapang. Formulasi yang tepat, selanjutnya akan digunakan untuk mendesain berbagai ukuran sumur. Ukuran terbaik dipilih berdasarkan kapasitas yang terbesar, dengan diameter yang sama. Dengan demikian, parameter kedalaman sumur menjadi factor yang dioptimasi. 


\section{Faktor Geometrik Sumur (F)}

Faktor geometrik (shape factor) adalah suatu harga yang mewakili dari bentuk ujung sumur, tampang, radius, kekedapan dinding serta perletakannya dalam lapisan tanah. Faktor geometric berbeda-beda nilainya tergantung dari rumus yang digunakan.

Rumus faktor geometrik merupakan rumus yang dipengaruhi oleh bentuk dari sumur resapan itu sendiri, mulai dari ujung sumur, tampang, radius, kekedapan dinding serta perletakannya dalam lapisan tanah.

Faktor geometrik merupakan salah satu unsur yang digunakan untuk mencari nilai K (koefisien permeabilitas tanah).

Kemudian ada banyak peneliti yang mengembangkan rumus $\mathrm{F}$ untuk berbagai kondisi sumur, seperti:

Samsioe (1931), Harza (1935), Dachler (1936), Taylor (1948), Hvorslev (1951), Aravin (1965),

Sunjoto $(1989$ - 2002).

Harga ini dimunculkan pertama kali oleh Forchheimer (1930) dalam mencari K dari penelitiannya dengan percobaan sesuai dengan formula (2.1). Cara ini hanya menggunakan satu lubang bor saja tanpa sumur pantau seperti lazimnya pada formula Dupuit-Theim yang berbasis Darcy's Law (1856) yang harus menggunakan sumur pantau. Cara Forchheimer ini memberikan kemudahan dalam perhitungan perencanaan karena secara eksplisit dapat menghitung dengan data laboratorium tanpa harus mengetahui data sumur pantau yang baru bisa diukur setelah pengaliran terjadi di lapangan. Maka konsep Forchheimer ini dapat disebut sebagai mashub baru dalam perhitungan Groundwater Flow selain konsep yang sudah ada yaitu Darcy's Law.

\section{HASIL DAN PEMBAHASAN}

\section{Curah Hujan}

Tabel 1. Data Curah Hujan Maksimum Tahunan

\begin{tabular}{|c|c|c|c|c|c|}
\hline No. & $\begin{array}{l}\text { R maks } \\
(\mathrm{mm})\end{array}$ & $\begin{array}{c}\text { Peluang } \\
(\%)\end{array}$ & $\log x$ & $\begin{array}{c}\log x- \\
\log x\end{array}$ & $(\log x-\log x)^{3}$ \\
\hline$(1)$ & $(2)$ & (3) & $(4)$ & (5) & (6) \\
\hline 1 & 58.55 & 0.04 & 1.7675 & $0 . \overline{-} 152$ & -0.0015 \\
\hline 2 & 61.17 & 0.09 & 1.7865 & $\begin{array}{c}- \\
0.0962\end{array}$ & -0.0009 \\
\hline 3 & 61.28 & 0.13 & 1.7873 & $\begin{array}{c}- \\
0.0954\end{array}$ & -0.0009 \\
\hline 4 & 62.82 & 0.17 & 1.7981 & $\begin{array}{c}- \\
0.0847\end{array}$ & -0.0006 \\
\hline 5 & 63.53 & 0.22 & 1.8030 & 0.0798 & -0.0005 \\
\hline 6 & 66.78 & 0.26 & 1.8246 & $\begin{array}{c}- \\
0.0581\end{array}$ & -0.0002 \\
\hline 7 & 70.92 & 0.30 & 1.8508 & $\begin{array}{c}- \\
0.0320\end{array}$ & 0.0000 \\
\hline 8 & 71.74 & 0.35 & 1.8558 & 0.0270 & 0.0000 \\
\hline 9 & 72.26 & 0.39 & 1.8589 & $\begin{array}{c}- \\
0.0239\end{array}$ & 0.0000 \\
\hline 10 & 74.99 & 0.43 & 1.8750 & $\begin{array}{c}- \\
0.0078\end{array}$ & 0.0000 \\
\hline 11 & 75.04 & 0.48 & 1.8753 & 0.0075 & 0.0000 \\
\hline 12 & 76.83 & 0.52 & 1.8855 & 0.0028 & 0.0000 \\
\hline 13 & 80.25 & 0.57 & 1.9044 & 0.0217 & 0.0000 \\
\hline 14 & 81.83 & 0.61 & 1.9129 & 0.0302 & 0.0000 \\
\hline 15 & 83.98 & 0.65 & 1.9242 & 0.0414 & 0.0001 \\
\hline
\end{tabular}


JURNAL INFOMANPRO

p-ISSN 2460-9609

e-ISSN 2774-7956

\begin{tabular}{|l|l|l|l|l|l|}
16 & 83.98 & 0.70 & 1.9242 & 0.0414 & 0.0001 \\
17 & 85.67 & 0.74 & 1.9328 & 0.0501 & 0.0001 \\
18 & 87.99 & 0.78 & 1.9444 & 0.0617 & 0.0002 \\
19 & 88.86 & 0.83 & 1.9487 & 0.0659 & 0.0003 \\
20 & 91.52 & 0.87 & 1.9615 & 0.0788 & 0.0005 \\
21 & 98.56 & 0.91 & 1.9937 & 0.1109 & 0.0014 \\
22 & 101.27 & 0.96 & 2.0055 & 0.1227 & 0.0018 \\
\hline jumlah & & 41.4207 & 0.0000 & -0.0001 \\
rata- & & 1.88276 & 0.0000 & 0.0000 \\
rata & & 0.0690 & 0.0690 & 0.0007 \\
standart devasi & & &
\end{tabular}

sumber : hasil perhitungan

Tabel 2. Perhitungan Curah Hujan Rencana

\begin{tabular}{|c|c|c|c|c|c|c|c|}
\hline \multirow{2}{*}{$\begin{array}{c}\mathrm{Tr} \\
\text { (tahun) }\end{array}$} & \multirow{2}{*}{$\begin{array}{c}\text { R rata } \\
(\log )\end{array}$} & \multirow{2}{*}{$\begin{array}{c}\text { Std Deviasi } \\
(\log )\end{array}$} & \multirow{2}{*}{$\begin{array}{c}\text { Kemencengan } \\
\text { (Cs) }\end{array}$} & \multirow{2}{*}{$\begin{array}{c}\text { Peluang } \\
(\%)\end{array}$} & \multirow[t]{2}{*}{$\mathrm{K}$} & \multicolumn{2}{|c|}{$\mathrm{R}$ rencana } \\
\hline & & & & & & $\log$ & $(\mathrm{mm})$ \\
\hline 5 & 1.8828 & 0.0690 & -0.0223 & 20 & 0.843 & 1.94 & 87.29 \\
\hline 10 & 1.8828 & 0.0690 & -0.0223 & 10 & 1.280 & 1.97 & 93.56 \\
\hline 15 & 1.8828 & 0.0690 & -0.0223 & 5 & 1.749 & 2.00 & 100.80 \\
\hline 20 & 1.8828 & 0.0690 & -0.0223 & 2 & 2.048 & 2.02 & 105.71 \\
\hline 25 & 1.8828 & 0.0690 & -0.0223 & 1 & 2.320 & 2.04 & 110.38 \\
\hline
\end{tabular}

sumber : hasil perhitungan

Tabel 3. Rekapitulasi Uji Smirnov Kolmogorof

\begin{tabular}{|c|c|c|c|c|c|}
\hline No & & $D_{\text {critis }}$ & $D_{\text {maks }}$ & \multicolumn{2}{|c|}{ Keterangan } \\
\hline 1 & $1 \%$ & 0.3475 & 0.0935 & $D_{\text {maks }}<D_{\text {critis }}$ & dipenuhi \\
2 & $5 \%$ & 0.29 & 0.0935 & $D_{\text {maks }}<D_{\text {critis }}$ & dipenuhi \\
\hline
\end{tabular}

sumber : hasil perhitungan

Tabel 4. Sebaran Hujan Jam-jaman Model Monobe

\begin{tabular}{|c|c|c|c|}
\hline $\begin{array}{c}\mathrm{T} \\
(\mathrm{jam})\end{array}$ & $\begin{array}{c}\mathrm{t} \\
(\mathrm{jam})\end{array}$ & & RT \\
\hline 1 & 6 & 0.550 & R24 \\
\hline 2 & 6 & 0.347 & R24 \\
\hline 3 & 6 & 0.265 & R24 \\
\hline 4 & 6 & 0.218 & R24 \\
\hline 5 & 6 & 0.188 & R24 \\
\hline 6 & 6 & 0.167 & R24 \\
\hline
\end{tabular}


sumber : hasil perhitungan

Keterangan :

$$
\begin{aligned}
& \text { RT } \quad=\text { R24/t . (t/T)2/3 } \\
& \text { RT =intensitas rata-rata hujan dalam } \mathrm{T} \text { jam }(\mathrm{mm} / \mathrm{hari}) \\
& \text { R24 =curah hujan efektif dalam } 1 \text { hari }(\mathrm{mm}) \\
& \mathrm{T} \quad \text { =waktu mulai hujan } \\
& \mathrm{t} \quad \text { =waktu konsentrasi hujan }
\end{aligned}
$$

\section{Koefisien Permeabilitas Tanah}

Untuk menentukan Permeabilitas tanah dilapangan digunakan percobaan sumuran uji. Pada waktu kedudukan muka air tetap telah tercapai,diperoleh data sbb :

Tabel 5. Koefisien Permeabilitas Tanah

\begin{tabular}{|l|l|}
\hline $\mathrm{q}=3,1 \mathrm{~m} 3 /$ menit & $\mathrm{r}^{1}=21 \mathrm{~m}$ \\
\hline $\mathrm{h}_{1}=5 \mathrm{~m}$ & $\mathrm{r}^{2}=50 \mathrm{~m}$ \\
\hline $\mathrm{h}_{2}=6 \mathrm{~m}$ & \\
\hline & \\
koefisien Permeabilitas Tanah : & \\
\hline
\end{tabular}

$$
\begin{aligned}
\mathrm{k} & =\frac{2,3 \cdot \mathrm{q} \cdot \log \left(\mathrm{r}_{1} / \mathrm{r}_{2}\right)}{\pi\left(\mathrm{h}_{2}{ }^{2}-\mathrm{h}_{1}{ }^{2}\right)} \\
& =\frac{2,3 \cdot(3,1 \mathrm{~m} 3 / \mathrm{menit}) \cdot \log (50 \mathrm{~m} / 21 \mathrm{~m})}{\pi\left(6 \mathrm{~m}^{2}-5 \mathrm{~m}^{2}\right)} \\
& =\frac{2,685}{34,558}=0,078 \mathrm{~m} / \mathrm{menit} \\
\mathrm{k} & =1,3 \times 10^{-3} \mathrm{~m} / \text { detik }
\end{aligned}
$$

Tabel 6. Periode Ulang

\begin{tabular}{|c|c|c|c|c|}
\hline Periode Ulang C & I & A & Q(m3/detik) & Q(m3/detik) \\
\hline 5 Tahun & & 21.620 & & 407.57 \\
\hline 10 Tahun & & 23.170 & & 436.79 \\
\hline 15 Tahun & 0,45 & 24.960 & 150,690 & 470.53 \\
\hline 20 Tahun & & 26.180 & 493.53 & \\
\hline 25 Tahun & & 27.33 & 515.21 & \\
\hline
\end{tabular}

\section{KESIMPULAN DAN SARAN}

\section{Kesimpulan}

Dari hasil analisis yang telah dilakukan maka didapatkan kesimpulan bahwa debit air hujan yang masuk ke dalam sistem akuifer tidak tertekan melalui proses infiltrasi pada DAS dengan periode ulang 5 tahun, 10 tahun, 15 tahun, 20 tahun, dan 25 tahun.

\section{Saran}

Dari hasil analisis perhitungan yang telah dilakukan, disarankan perlu membuat beberapa sumur resapan karena kurangnya resapan air yang menyebabkan air limpasan besar pada daerah DAS agar dapat mengurangi genangan yang ada pada daerah tersebut. 


\section{DAFTAR PUSTAKA}

Bastin Yungga Angguniko. 2010. Persepsi Masyarakat Terhadap Teknologi Sumur Resapan dan Lubang Resapan Biopori (Studi kasus: Kabupaten Tangerang Selatan). Jurnal Sosek Pekerjaan Umum, Vol.2 No.1, April 2010 Hal 9-2067-80.

Dinas Energi Dan Sumber Daya Mineral Provinsi Jawa Tengah. 2017. Pembuatan Sumur Gali/ Pasak Di Jawa Tengah. Kerangka Acuan Kerja (Kak). Tidak Diterbitkan.

Kustamar.2016. Konservasi Sumber Daya Air Di Hulu DAS. Prosiding Temu Ilmiah Iplbi 2016.

Kustamar (2017). Strategy To Increase Absorption Well Capacity. Journal Of Technology And Sciences. Vol.1 No. 1

SNI: 03-2453. (2002). Tata Cara Perencanaan Sumur Resapan Air Hujan Untuk Lahan Pekarangan. Jakarta: Badan Standardisasi Nasional.

SNI: 8456. (2017). Sumur dan Parit Resapan Air Hujan. Jakarta: Badan Standardisasi Nasional.

Sunjoto. (2011). Teknik Drainase PRO-AIR. Yogyakarta: Universitas Gadjah 